\title{
Observations of Sympatric Populations of Least Chipmunks (Tamias minimus) and Hopi Chipmunks (Tamias rufus) in Western Colorado, 1995-2006
}

\author{
Jeffrey B. Doty, ${ }^{1}$ J. Jeffrey Root, ${ }^{1,2}$ and Charles H. Calisher ${ }^{1}$ \\ ${ }^{1}$ Arthropod-Borne and Infectious Diseases Laboratory, Department of Microbiology, College of Veterinarian Medicine and \\ Biomedical Sciences, Colorado State University, Fort Collins, CO 80523, USA \\ ${ }^{2}$ U.S. Department of Agriculture, Wildlife Services, National Wildlife Research Center, Fort Collins, CO 80521, USA
}

Correspondence should be addressed to Jeffrey B. Doty, jdoty@colostate.edu

Received 15 June 2009; Accepted 15 December 2009

Recommended by Bruce Leopold

From 1995 through 2006, we studied a rodent community in western Colorado, observing weather conditions and their effects on least chipmunk (Tamias minimus) and Hopi chipmunk (T. rufus) populations. There are few studies that have assessed relative abundances of chipmunks over long durations and none have been conducted on least chipmunks or Hopi chipmunks. This study is unique in that it assesses abundances of sympatric populations of these chipmunks over a 12-year period. We captured 116 least chipmunks and 62 Hopi chipmunks during 47,850 trap nights of effort. Results indicated that year-to-year precipitation and temperature fluctuations had little effect on these chipmunk populations. However, the relative abundances of Hopi chipmunks and least chipmunks appear to have an inverse relationship with each other, suggesting the potential for resource competition between these congeners.

Copyright (c) 2009 Jeffrey B. Doty et al. This is an open access article distributed under the Creative Commons Attribution License, which permits unrestricted use, distribution, and reproduction in any medium, provided the original work is properly cited.

\section{Introduction}

Numerous and detailed studies have shown that multiple variables contribute to changes in relative sizes of rodent populations. Among these are availability of food and water [1], variations in seasonal changes [2,3], competition with other species $[4,5]$, and the presence of predators [6].

Least chipmunks (Tamias minimus) can be found throughout most of Canada and widely in the western U.S, whereas the Hopi chipmunk (T. rufus) is limited to northern Arizona, eastern Utah, and western Colorado [7]. As immediate sources of food and for hoarding, chipmunks of each species harvest seeds and nuts as well as fruits and berries. They also include in their diets arthropods and fungi, if supplies of other food sources are not available $[8,9]$. Under laboratory conditions least chipmunks consume about 30\% less water than do alpine chipmunks (T. alpinus), lodgepole chipmunks ( $T$. speciosus), or yellow-pine chipmunks ( $T$. amoenus), and are able to concentrate urine in dry habitat [10]. In contrast, when Hopi chipmunks are deprived of water, they will die within about two days [8].
Few studies of least chipmunk or Hopi chipmunk population fluctuations, even over relatively brief periods, have been published, but results of studies of population changes in a related species, the eastern chipmunk (T. striatus), are available. Wolff [1] reported that increased acorn production in a given year corresponded with an increase in the abundance of eastern chipmunks the following summer. Merritt et al. [2] reported that an increase in snowfall in a given winter was related to increased numbers of eastern chipmunks in the following months in Pennsylvania, but that summer precipitation did not have a similar effect on the number of chipmunks there.

From 1995 to 2006, we collected data intended to elucidate the relationship between the sizes of rodent populations, principally deer mice (Peromyscus maniculatus), and the prevalence of hantaviruses in western Colorado [11]. Because we also were interested in others of the rodent community at the site, we also captured least chipmunks and Hopi chipmunks, providing an opportunity to monitor fluctuations of their populations over an extended time period. 
We are unaware of published reports on the population dynamics of these chipmunks and how they relate to seasonal climatic variations. Therefore, the objective of this study was to evaluate changes in air temperature and precipitation and compare these climatic variables to fluctuations in the relative abundances of these chipmunks over a 12-year period.

\section{Methods}

The study site was located in Mesa County near Molina (elevation $\sim 2,100 \mathrm{~m}$ ) in the foothills of Grand Mesa. The flora is characterized primarily by Rocky Mountain juniper (Juniperus scopulorum), piñon pine (Pinus edulis), rabbitbrush (Chrysothamnus spp.), sage (Artemesia spp.), yucca (Yucca spp.), cacti (Opuntia spp.), and grasses (Bouteloua spp. and Poa spp.).

Two permanent mark-recapture trapping webs were established and spaced about $640 \mathrm{~m}$ apart. These webs were separated by a ditch periodically filled for irrigation but that likely did not limit the dispersion of rodents. Web A was comprised principally of sagebrush and bare ground, with interspersed grasses and forbs. This vegetation type was typical of the area and was represented almost exclusively in the central and northern portion of this web. The eastern portions of this web slopes down toward a pasture used for livestock grazing; this slope was characterized by piñon pines and junipers, with sparse undergrowth among rocks and juniper deadfall. The southern and western edges of web A were comprised of piñon-juniper woodland. Web B was essentially flat, with piñon, juniper, and sagebrush scattered throughout but with less sagebrush and more juniper than occur at web A.

Detailed descriptions of the study site, trapping procedures, and results of other aspects of these investigations have been published previously [12-14]. Each web consisted of 145 trap stations arranged in 12 lines of 12 traps each, radiating from a single trap station at the center of the web, with lines being $30^{\circ}$ apart from one another [13]. The inner four trap stations of each line (near the center of the web) were spaced $5 \mathrm{~m}$ apart and the outer eight trap stations were $10 \mathrm{~m}$ apart. One $8 \times 9 \times 23 \mathrm{~cm}$ nonfolding Sherman livetrap (H.B. Sherman Traps, Inc., Tallahassee, FL) was placed at each trap station and baited with a mixture of rolled oats, cracked corn, and peanut butter. Traps were generally set during the afternoon on the first day and were checked for three or rarely two $(n=6)$ consecutive mornings during each trapping session $(n=57)$.

Mark-recapture trapping was conducted each six weeks beginning in May 1995, as weather permitted, and ending in October 2006. Due to logistical constraints, including snow cover and mud from snow melt, trapping was not typically conducted during the winter and early spring months (November-March).

During every trapping session, the number of chipmunks captured was recorded. In addition, the fate of each animal (e.g., new capture, recapture, etc.) was noted for relative abundance analyses. The minimum number alive (MNA;
[15]) was calculated for each trapping session and the mean MNA was calculated by year and season (April-May = spring, June-August $=$ summer, and September-October $=$ fall). The MNA has been shown to be a reliable estimate of population size and typically is within 10 percent of the actual number of animals if trapability is high [16].

Air temperature and precipitation data from December 1994 to May 2002 were acquired from the National Oceanic and Atmospheric Administration website (http://www.noaa.com); these data were unavailable for May 1996 through April 1997. From May 2002 until October 2006, an automated meteorological station (Campbell Scientific, Logan, UT) was used to record air temperature and precipitation data. Meteorological data were organized by season (December-February = winter, March-May = spring, June-August $=$ summer, and September-November $=$ fall) for correlational studies with seasonal chipmunk abundances.

Juniper berry production was assessed from 2001 to 2006. Twenty-five juniper trees within each web were selected from individuals across five age classes (based upon the radius of the tree canopy). We estimated the relative number of branches with berries and the relative number of berries per branch for each tree. This was used to create a juniper berry index (per site mean of age class $\times$ branches with berries $\times$ berries per branch) which we could compare from year-to-year. The protocol we were following for the monitoring of deer mouse populations did not require the assessment of piñon nut production and therefore this was not conducted. These data collection protocols were standardized so the data could be included in meta-analyses with data collected at other sites in the intermountain west.

The product-moment correlation coefficient [17] with a significance level of 0.05 was used to test for associations between the mean seasonal MNA of these chipmunks and the weather variables. Associations using three- and sixmonth time lags were also assessed for seasonal chipmunk abundances and weather variables. Separate correlation coefficients were calculated to test for associations between the mean annual MNA of these chipmunks, the annual weather data, and the juniper berry indices. All variables were transformed to the natural log prior to use in the correlations.

\section{Results}

Results from the two trapping webs did not differ and therefore these data were pooled. During 47,850 trap nights (May 1995 to October 2006), 116 individual least chipmunks and 62 individual Hopi chipmunks were captured. Twenty-five least chipmunks and 21 Hopi chipmunks were recaptured, yielding $21.6 \%$ and $33.9 \%$ recapture rates, respectively. The longest interval between the first and last captures was 23 months (mean $=7.6 \pm 5.4 \mathrm{SD}$ ) for least chipmunks and 14 months (mean $=4.6 \pm 4.5 \mathrm{SD}$ ) for Hopi chipmunks. Least chipmunks were generally more abundant than were Hopi chipmunks; however, from autumn 1997 to 


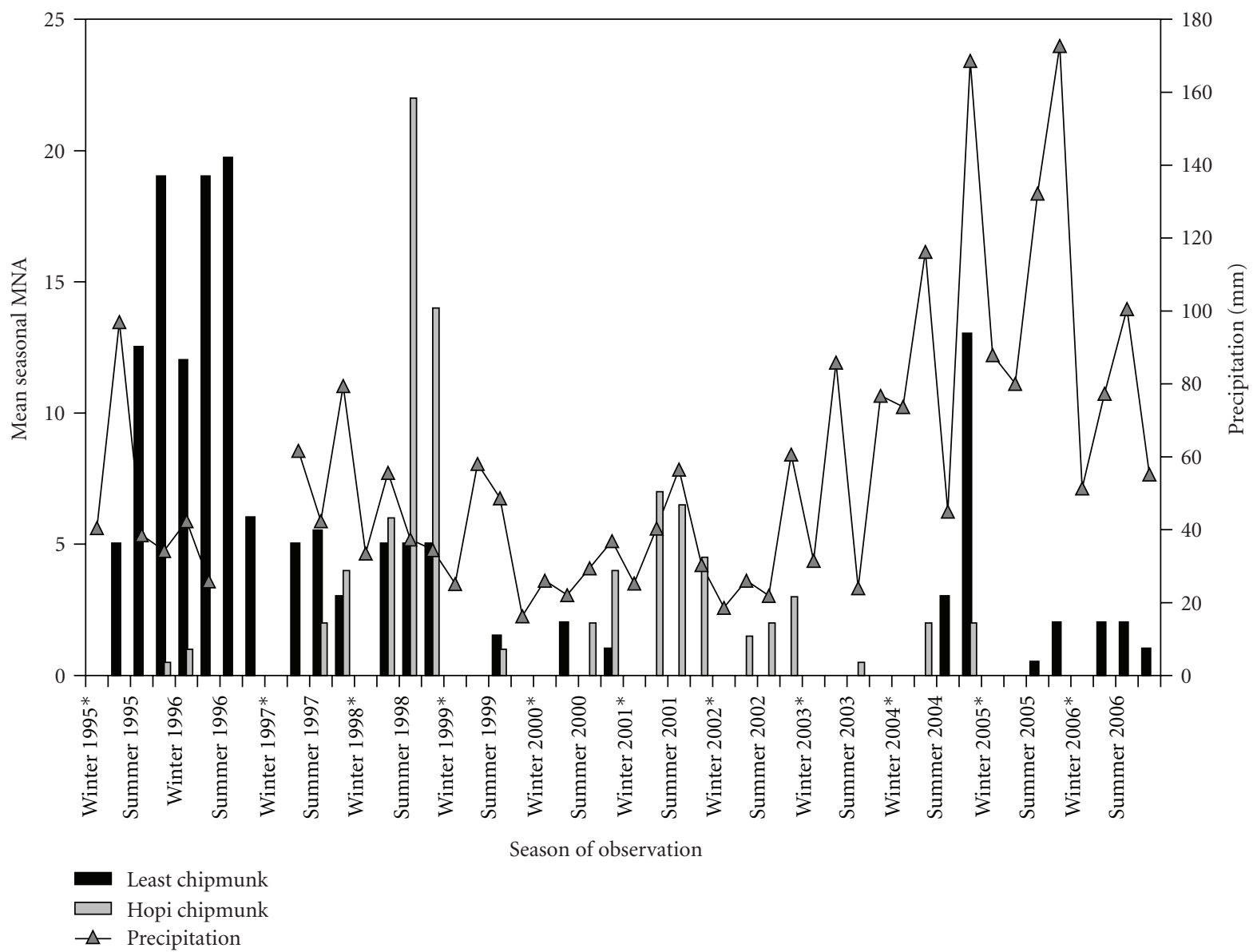

FIgURE 1: Mean minimum number of chipmunks alive (MNA) and precipitation at Molina, Colorado by season. * Indicates winters when trapping was not conducted.

autumn 1998 and from summer 1999 to spring 2004 more Hopi chipmunks were captured than were least chipmunks (Figure 1).

No significant correlations were found between the mean seasonal MNAs of these chipmunks ( $n=34, r=-0.17)$. However, a weak inverse relationship was observed between least chipmunk abundance (declined in 1996 and 1997) and Hopi chipmunk abundance (increased in 1997 and peaked in 1998). A general decline of both chipmunk populations was observed after 1998. We captured 14 juvenile and three subadult least chipmunks and two juvenile and no subadult Hopi chipmunks during this study. Therefore, age structures of these populations could not be accurately assessed with these data.

Peromyscine rodents (P. maniculatus and P. truei) were also captured during this study. During 870 trap nights per trapping session, $15-253$ (mean $=65.1 \pm 47.5 \mathrm{SD}$ ) peromyscine captures were recorded. Due to these traps being occupied by peromyscine rodents, a maximum of 617-855 traps per trap session were available overnight and during early morning for chipmunks to be captured. However, chipmunks had the first opportunity to be captured in late afternoon and evening because of their diurnal activity patterns, whereas peromyscine rodents are nocturnal.
Total precipitation was greatest in 2004-2005, and least in the summer of 1994, the fall of 1999, and the winter of 2002 (Figure 1). Although year-to-year differences between mean seasonal temperatures were small and therefore are not presented, the winters of 1994 and 1999 were the coolest, whereas the summers of 2000, 2002, and 2003 were the warmest. No significant correlations were found between these weather variables and chipmunk abundances without a time lag, with a three month lag, or with a six month lag.

Juniper berries were produced each year that they were assessed, with peak production from 2003 to 2005 (Figure 2). This occurred while an increase in rainfall and a moderate increase in least chipmunk abundance were recorded. Juniper berry production was significantly correlated with annual precipitation $(n=6, r=0.83)$ but the annual mean MNA of neither chipmunk population was significantly correlated with juniper berry production. No correlations were found between juniper berry production and fall MNA or the following spring or summer MNA for either species.

\section{Discussion}

These data suggest that precipitation and temperature had little effect on populations of least or Hopi chipmunks, 


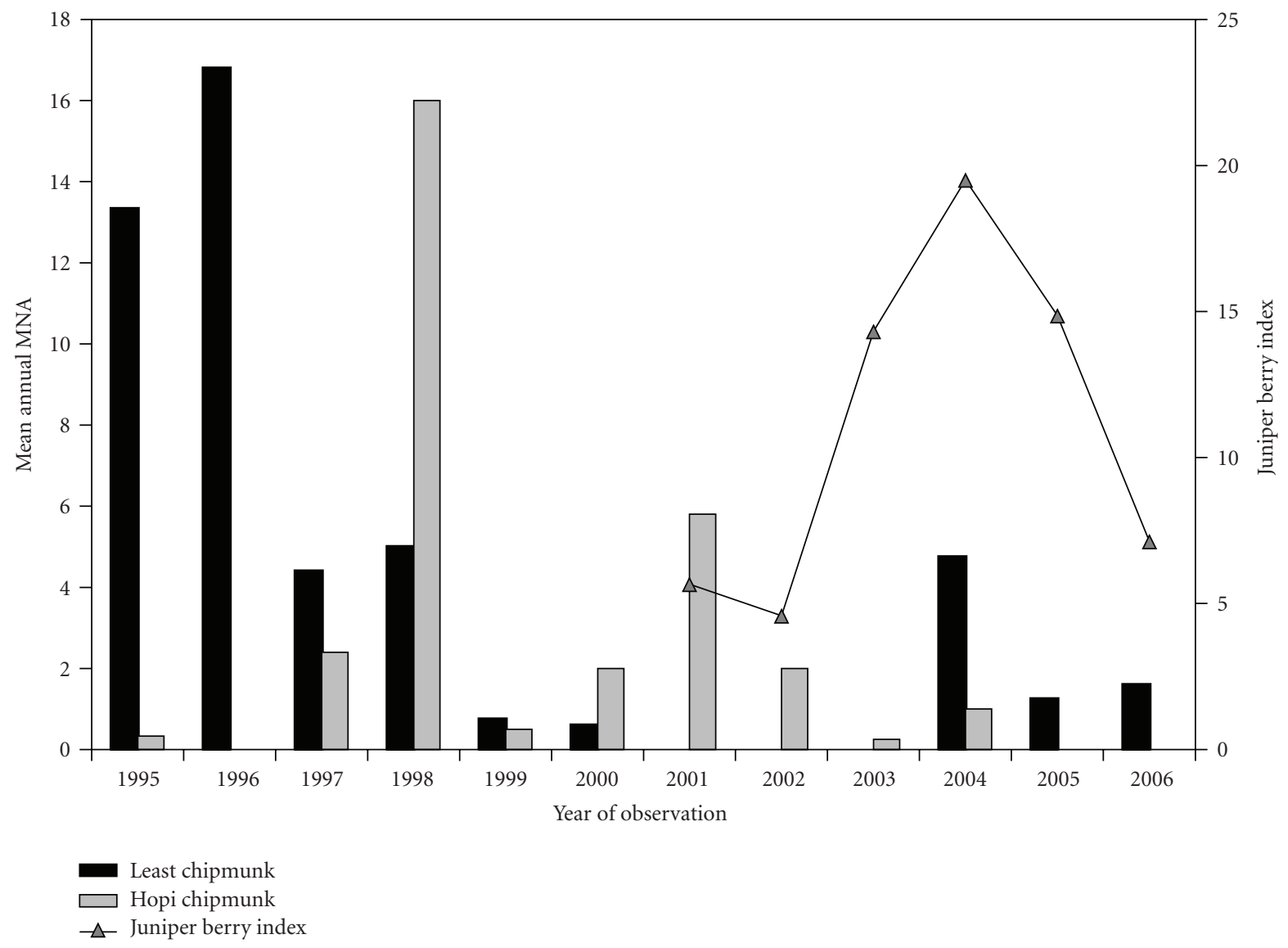

FIGURE 2: Annual juniper berry production and mean annual minimum number alive (MNA) of chipmunks at Molina, Colorado.

although there was an increase in the least chipmunk population in late 2004, when precipitation increased from previous years of this study. Least chipmunks are generalists, able to exploit a variety of habitats and resources [9]. Therefore, they likely are able to adjust their diets based upon resource availability during periods of adverse conditions. It is possible that averaging MNAs by season has masked climatic effects on these populations, although we observed similar patterns when assessing these data by trapping session.

Some chipmunks captured during this study were likely dispersing from adjacent areas; however, we recorded very few captures of juvenile and subadult chipmunks, which are generally thought of as being dispersers. Sexual preparedness in male least chipmunks occurs from March to June but females are breeding-prepared before they emerge from their winter dens and they enter estrus within a week of emergence [9]. Mating occurs between April and mid-May and gestation lasts, 28 to 30 days, producing one litter of 5 to 6 pups annually [10]. Hopi chipmunks are sexually active from February to mid-April and gestation lasts 30 to 33 days; they also produce one litter of 5 to 6 pups each year [8]. Since chipmunk mating and birthing generally occur in the spring, adverse weather conditions during that time might eliminate breeding for that year.
Least chipmunks have been shown to be excluded from piñon juniper woodlands and conifer forests by yellow pine chipmunks and lodgepole chipmunks [18, 19]. Root et al. [4] showed that when Hopi chipmunk populations increased, least chipmunks were more commonly found in sagebrush habitat and were found less commonly in piñon juniper habitat. Those reports suggest that Hopi chipmunks may be better able to exploit the juniper berry resource than are least chipmunks, although our data regarding juniper berry production and chipmunk abundances neither support nor reject this idea. Further studies of juniper berry production and chipmunk abundance should be conducted in order to accurately assess this relationship.

Hopi chipmunks have been found to be associated with piñon-juniper habitats across much of their range and have been reported to feed extensively on juniper berries in Utah $[7,8]$. Although we found no association between juniper berry production and chipmunk abundance, we did not begin assessing juniper berry production until 2001, when abundances of both species were considerably lower than they were at the beginning of this study. However, we observed an increase in abundance of least chipmunks during the fall of 2004 when juniper berry production was at its peak. This increase in least chipmunk abundance likely occurred before a plentiful juniper berry crop could 
have influenced the size of the least chipmunk population. Therefore, the reasons for this abundance increase are unknown but could have been influenced by increased precipitation during that year.

Relative abundances of least and Hopi chipmunks show a weak inverse relationship. When least chipmunk abundance decreased in 1997, Hopi chipmunk abundance began to increase, peaking in 1998. After Hopi chipmunk abundance reached a nadir in 2003 and 2004, the abundance of least chipmunks increased. This suggests that these two chipmunks may have been competing for resources during this period, which included adverse weather conditions. Alternatively, these data also suggest that Hopi chipmunks may be better able to survive during adverse climatic conditions in these piñon-juniper habitats for which they seem to be adapted. Effects of interspecific and competitive interactions on chipmunk population sizes are not well documented and require further investigations to assess these relationships.

\section{Acknowledgments}

The authors thank Nina Leuschen, Dorothy Trawick, and Michelle D. Keefer, students at Colorado State University, for assisting in data summaries and analyses. In addition, we thank Ms Robin Carns, Mesa County Health Department, Grand Junction, Colorado, Dr. Tony Schountz, University of Northern Colorado, and his students from Mesa State College, including Ms Marcia Patterson-Hernandez, Mr. Louis Starzel, Jr., Ms Emily Kampf, and Ms Jodi Grewell for their assistance. we also thank two anonymous reviewers and the editors of this journal for comments on an earlier draft of this manuscript. Funding for this work was provided by the U.S. Centers for Disease Control and Prevention, Atlanta, GA under cooperative agreement no. U50/ccu809862-03 and the National Institutes of Health contract AI-25489, for which the authors are grateful.

\section{References}

[1] J. O. Wolff, "Population fluctuations of mast-eating rodents are correlated with production of acorns," Journal of Mammalogy, vol. 77, no. 3, pp. 850-856, 1996.

[2] J. F. Merritt, M. Lima, and F. Bozinovic, "Seasonal regulation in fluctuating small mammal populations: feedback structure and climate," Oikos, vol. 94, no. 3, pp. 505-514, 2001.

[3] R. H. Yahner and G. E. Svendsen, "Effects of climate on the circannual rhythm of the Eastern chipmunk, Tamias striatus," Journal of Mammalogy, vol. 59, pp. 109-117, 1978.

[4] J. J. Root, C. H. Calisher, and B. J. Beaty, "Microhabitat partitioning by two chipmunk species (Tamias) in western Colorado," Western North American Naturalist, vol. 61, no. 1, pp. 114-118, 2001.

[5] J. B. Doty, C. H. Calisher, J. J. Root, and B. J. Beaty, "Microhabitat use by deer mice in response to fluctuations in pinyon mouse abundance," Intermountain Journal of Sciences, vol. 12, pp. 54-60, 2006.

[6] J. L. Orrock, B. J. Danielson, and R. J. Brinkerhoff, "Rodent foraging is affected by indirect, but not by direct, cues of predation risk," Behavioral Ecology, vol. 15, no. 3, pp. 433-437, 2004.

[7] J. P. Fitzgerald, C. A. Meaney, and D. M. Armstrong, Mammals of Colorado, University Press of Colorado, Niwot, Colo, USA, 1994.

[8] S. L. Burt and T. L. Best, "Tamias rufus," Mammalian Species, no. 460, pp. 1-6, 1994.

[9] B. J. Verts and L. N. Carraway, “Tamias minimus," Mammalian Species, no. 633, pp. 1-10, 2001.

[10] H. C. Heller and D. M. Gates, "Altitudinal zonation of chipmunks (Eutamias): energy budgets," Ecology, vol. 52, pp. 424-433, 1971.

[11] C. H. Calisher, J. J. Root, J. N. Mills, and B. J. Beaty, "Assessment of ecologic and biologic factors leading to hantavirus pulmonary syndrome, Colorado, U.S.A," Croatian Medical Journal, vol. 43, no. 3, pp. 330-337, 2002.

[12] C. H. Calisher, W. Sweeney, J. N. Mills, and B. J. Beaty, "Natural history of Sin Nombre virus in western Colorado," Emerging Infectious Diseases, vol. 5, no. 1, pp. 126-134, 1999.

[13] J. N. Mills, T. L. Yates, T. G. Ksiazek, C. J. Peters, and J. E. Childs, "Long-term studies of hantavirus reservoir populations in the southwestern United States: rationale, potential, and methods," Emerging Infectious Diseases, vol. 5, no. 1, pp. 95-101, 1999.

[14] C. H. Calisher, J. N. Mills, J. J. Root, J. B. Doty, and B. J. Beaty, "Environmental factors influence transmission of Sin Nombre hantavirus between rodents (and to humans?)," in Proceedings of the Vector-Borne Diseases: Understanding the Environmental, Human Health, and Ecological Connections Workshop, pp. 200217, The National Academies Press, Washington, DC, USA, 2008.

[15] D. Chitty and E. Phipps, "Seasonal changes in survival in mixed populations of two species of vole," Journal of Animal Ecology, vol. 35, pp. 313-331, 1966.

[16] R. Hilborn, J. A. Redfield, and C. J. Krebs, "On the reliability of enumeration for mark and recapture census of voles," Canadian Journal of Zoology, vol. 54, pp. 1019-1024, 1976.

[17] R. R. Sokal and F. J. Rohlf, Biometry, W. H. Freeman, New York, NY, USA, 3rd edition, 1995.

[18] D. Sheppard, "Competition between two chipmunk species (Eutamias)," Ecology, vol. 52, pp. 320-329, 1971.

[19] D. H. Meredith, "Interspecific agonism in two parapatric species of chipmunks (Eutamias)," Ecology, vol. 58, pp. 423430, 1977. 

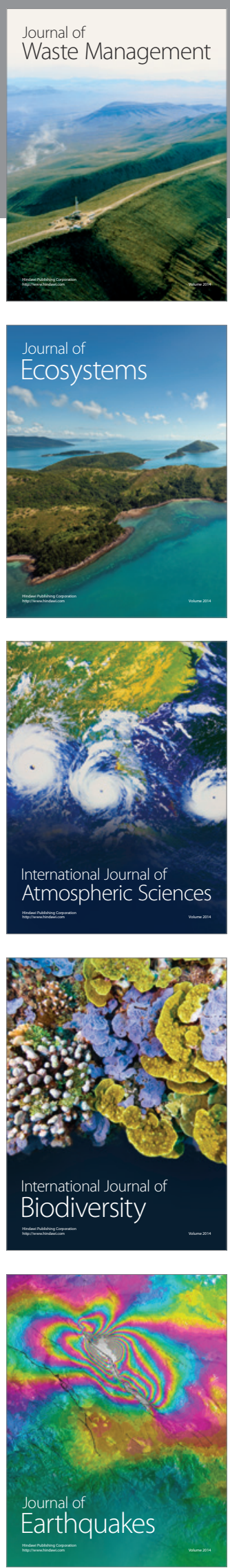
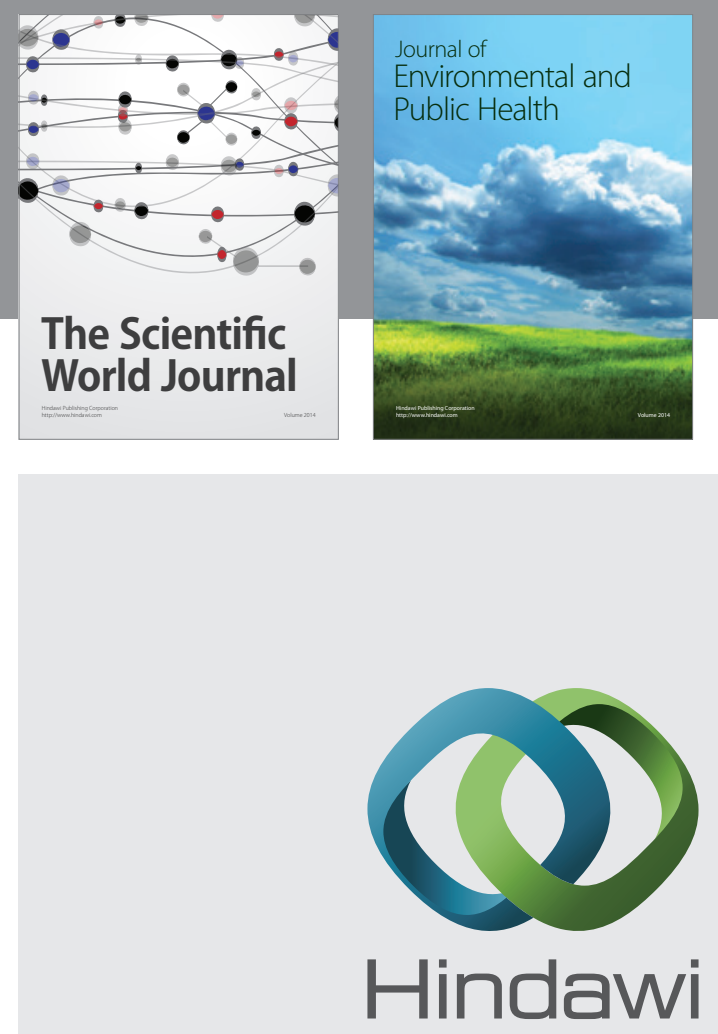

Submit your manuscripts at

http://www.hindawi.com
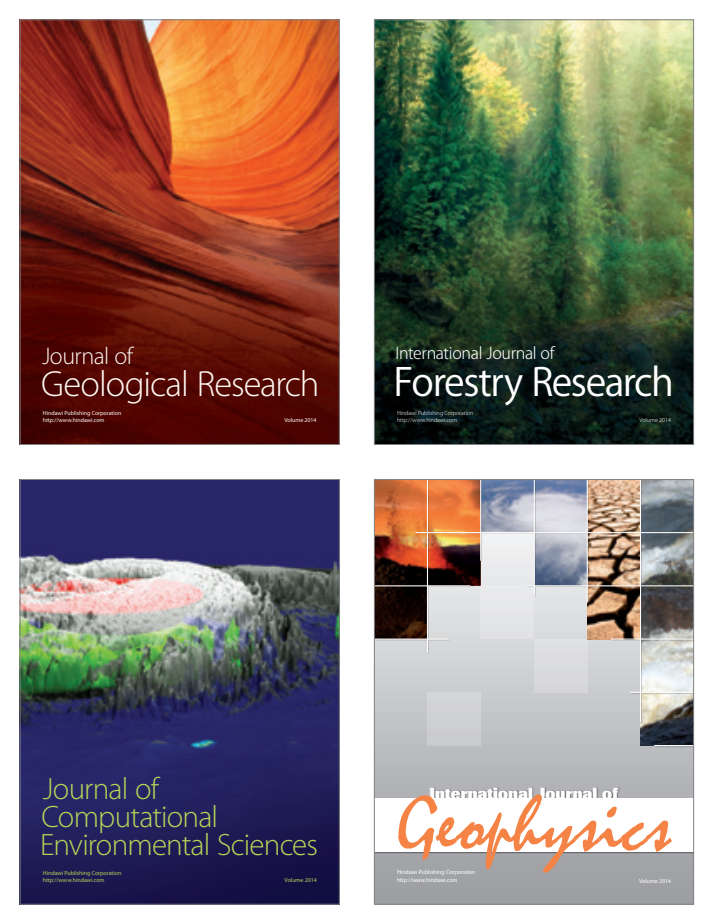
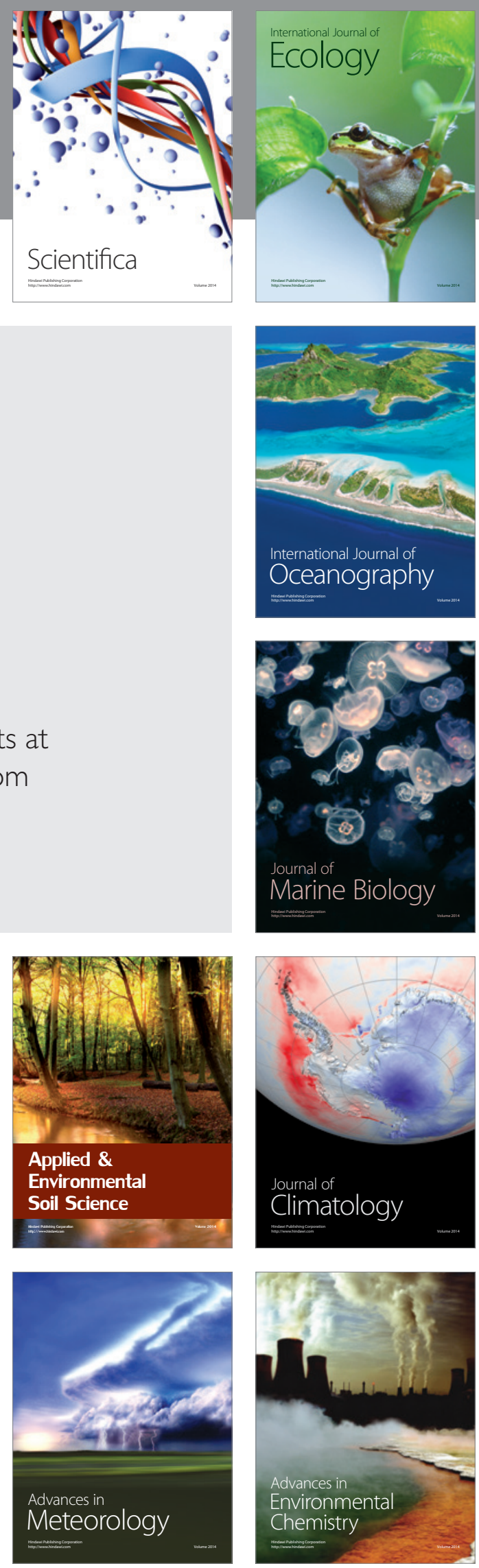